\title{
Ethics Committees in Pandemic Period: Dawn of a New Era
}

\section{Pandemi Döneminde Etik Kurullar: Yeni Bir Çağın Şafağı}

\section{(D) Adil Polat}

Chariman of Institutional Ethics Committee, University of Health Sciences Turkey, İstanbul Bağcllar Training and Research Hospital, Clinic of Cardiovascular Surgery, İstanbul, Turkey

\section{Dear Editor,}

Novel coronavirus caused a severe outbreak worldwide and the first case in Turkey was reported in March 2020. Rapid preventive actions were taken by the government in all areas of life. Clinical investigations became a topic of interest in this period. In the core of this research environment, ethics committees were asked for guidance and ethical considerations. The pandemic period has affected the clinical research environment in many ways. This may be the first report of experience during Coronavirus diseases-2019 pandemic from an ethics committee in Turkey.

The World Health Organization released guidelines for managing infectious disease outbreaks in 2016 after the Ebola outbreak in West Africa in 2015 (1). The aforementioned World Health Organization guideline (1) addresses some questions in ethics review in terms of time limitations, problems about expertise and the probable pressures from authorities which may limit the independence of researchers. Time limitations and the search for mechanisms of disease and the probable treatment modalities enable researchers work in the related outbreak. The urge for treatment and need for understanding the disease dictate rapid evaluation processes. However, even for the sake of this need, ethical issues cannot be overlooked. The authorities should enable the ethics committees with tools to overcome difficulties with the increased research needs.
Many authorities in many different countries have released regulations in order to control the immediate problems as the disease outbreak was evident (2). The European Network of Research Committees has also released a position statement for this pandemic period, addressing many issues including digital communication systems and their use in committee procedures (3). The Ministry of Health released the guidelines for the researchers and ethics committees very rapidly $(4,5)$. First one (5) was released on March 19th and the revision on July $24^{\text {th }}$. According to these regulations, direct meetings were canceled and web-based meetings were recommended using a recommended programme (6). Whenever possible, signatures of the members of the ethics committee were required for the decision papers.

Similar experiences have been reported from India (7-9). I would like to summarize some problems and solutions which were imminent and were successfully solved during the outbreak. There are still some problems that need to be addressed and the probable solutions will require financial support.

After the cases were announced in March 2020, our institutional ethics committee declared the transient suspension of ethics committee meetings. The primary reasons for this suspension were as follows:

(i) The secretary of the committee contracted the disease and the face-to-face file application process was found to be severely dangerous.

Address for Correspondence: Adil Polat, Chariman of Institutional Ethics Committee, University of Health Sciences Turkey, İstanbul Bağcllar Training and Research Hospital, Clinic of Cardiovascular Surgery, İstanbul, Turkey

E-mail: adilpol@yahoo.com ORCID ID: orcid.org/0000-0002-4043-7421 Received: 02.11.2020 Accepted: 09.12.2020

Cite this article as: Polat A. Ethics Committees in Pandemic Period: Dawn of a New Era. Bagcilar Med Bull 2021;6(1):92-94.

(C) Copyright 2021 by the Health Sciences University Turkey, Bagcilar Training and Research Hospital

Bagcilar Medical Bulletin published by Galenos Publishing House. 
(ii) Our committee consists of 11 members, 5 of whom are outside the hospital. The external members of the committee were reluctant to join the meetings which were routinely made in the ethics committee room in the hospital and our hospital was one of the busiest pandemic hospitals of the region.

(iii) Need for a guideline from the authority.

After the guideline was released in March 2020 (4), the preparations were made in order to form a continuous application and evaluation processes and the system for meetings were prepared. Since there was no financial support for ethics committee, all available free-of-charge systems were utilized.

In University of Health Sciences Turkey, İstanbul Bağcılar Training and Research Hospital Ethics Committee, the following protocol has been utilized since May 2020: All applications are accepted by e-mail to the official mail address. All application papers were required to be complete with all signatures of all researchers. The signed papers were required to be scanned and the digital forms were sent to the committee's e-mail. After the review process by the reporters, applications were evaluated in the regular meetings which were made in every 2 weeks. The decision papers were prepared according to the circular letter sent by the Ministry. The decision papers were prepared in Word program and transformed to pdf format. In pdf format with a cover letter, the paper was digitally signed by the ethics committee chairman. The members were asked to send their decisions on each application as a list in word program and those lists were asked to be sent to the committee's e-mail.

For a rapid comparison, following figures will be descriptive. Before the first case was announced and preventive measures were taken, 4 ethics committee meetings were made from the beginning of 2020. In these 4 meetings, total number of decisions was 32 . Of these 32 decisions, 29 were approved and 3 were rejected (90.6\% approval rate). After the meetings were restarted in May 2020, within the first 3 meetings, 52 decisions were made. Of these 52 decisions, the number of approvals was $47(90.4 \%)$. In spite of a rough figure, the following two conclusions could be withdrawn: (i) Researchers have adapted to the on-line application processes rapidly and the files could be prepared accordingly. (ii) As for the mid of October, the total number of decisions in 2020 is 161 . For a quick comparison; the total numbers of decisions in 2018 and 2019 (whole year) were 127 and 100, respectively. It is evident that pandemic period caused a rapid increase in the number of researches made in our institution.

The following issues, however, should be addressed for improved evaluation processes. First, on-line applications should be made through a more professional website, similar to medical journals with necessary adjustments. Our temporary solution, although proved to be effective, is highly demanding both for the applicants and committee members. Second, the quality of academic (or investigator initiated) studies needs evaluation. Our committee receives applications mainly from the researchers of our institution (in 2018 and 2019, 94.5\% and 95.0\%, respectively) with a small percentage of researches made in other institutions. There are almost no applications of researches supported by the medical or pharma industry. The investigator initiated research applications are made with difficulties for the applicants, which need to be addressed and solved by our committee secretary, which is a highly demanding task. An effective research education and certification process should be considered similar to the animal studies.

Another issue specific to our ethics committee is the high number of applications in traditional and complementary medicine (TCM). We have been receiving TCM applications from the beginning of our committee studies. During this outbreak, there was a severe surge in the number of TCM study applications. The problems in TCM researchers seem to be more serious compared to other clinical studies. One of the possible reasons is the recent introduction of TCM regulations in 2019 (10) and the lack of knowledge by the researchers. Another and more important issue is the lack of understanding by the researchers. Researchers share some problematic opinion about research. They commonly think that TCM interventions are harmless and researches can be made with less caution compared to classic clinical studies. The concepts of "equipoise" and "volunteer safety" is commonly ignored or overlooked. The common understanding of "natural substances or traditional interventions are harmless" poses important risks for the years to come.

One of the important problematic understanding can be summarized under the heading of equipoise. Most of the investigator initiated clinical studies have serious drawbacks for any equipoise in the studies. This is a serious problem in the thesis of residents in medicine, but other academic studies have similar problems as well. Researches are commonly performed for academic promotions and one can easily see that applicants made researches in the areas outside the areas of their interest or daily practice. 
Consequently, researchers have great difficulties in asking clinically relevant questions of debate.

The on-line meeting programme recommended by the authority (6) enabled committees to make on-line programmes despite a free charge software. As usual, we paid dearly since we bought cheaply. The programme has many problems that need to be solved and a continuous back-up was not available. Ethics committee procedures should be refined and be converted to digital area with necessary investment in order to achieve flawless ethics committee studies.

One of the biggest advantages of on-line applications for the applicants and committees is the ease in communication. Normally, applicants physically bring the files and the communication during applications is made either faceto-face or through telephone. During the outbreak period, the communications were made thorough e-mails which enabled the committee to document any communication. Although applicants insist on rapid immediate responses, the ease of communication seems to be working more efficiently as experience accumulates.

In conclusion, outbreaks have great opportunities for research environment along with the problems of their own. The ethics committees should focus on evaluation process without ignoring any necessary points even during the outbreak period. Application processes need refining and financial support for becoming more effective.

Keywords: Ethics, ethic committees, digital, pandemic

Anahtar kelimeler: Etik, etik kurul, dijital, pandemi

\section{Ethics}

Peer-review: Externally peer-reviewed.

Financial Disclosure: The author declared that this study received no financial support.

\section{References}

1. World Health Organization. Guidance for managing ethical issues in infectious disease outbreaks. Geneva, Switzerland: WHO; 2016 [cited 2020 May 4]. Available from: https://apps.who.int/iris/ handle/10665/250580 (Lastly visited: October 6th, 2020)

2. Meagher KM, Cummins NW, Bharucha AE, Badley AD, Chlan LL, Wright RS. COVID-19 Ethics and Research. Mayo Clin Proc 2020;95(6):1119-1123.

3. Position of the European Network of Research Ethics Committees (EUREC) on the Responsibility of Research Ethics Committees during the COVID-19 Pandemic. Available from: http://www. eurecnet.org/documents/Position_EUREC_COVID_19.pdf (Lastly visited in October 16th, 2020)

4. COVID-19 Pandemisi Nedeniyle Klinik Araştırmalarda Alınacak Tedbirler. Available from: https://titck.gov.tr/storage/ Archive/2020/announcement/ 8ca5ea8c-4933-446c-acd5de9384385f03.pdf (Lastly visited in October 6th, 2020)

5. COVID-19 Pandemisi Nedeniyle Klinik Araștırmalarda Alınacak Tedbirler. Available from: https://titck.gov.tr/storage/ Archive/2020/announcement /COVID19KATedbirlerv2.0_ ed21cd3b-4e35-4ff1-a109-f74540a2683b.pdf (Lastly visited in October 6th, 2020)

6. Available from: birlikte.titck.gov.tr (Lastly visited in October 6th, 2020)

7. Agrawal V, Nath C, Mishra SK. Ethics committee meeting by videoconferencing during Covid-19. Indian J Med Ethics, 2020; doi: 10.20529/IJME.2020.062 (Online ahead of print)

8. Ghooi RB. Ethics committee meetings - Online or face to face? Perspect Clin Res 2020;11(3):121-123.

9. Bavdekar SB. Ethics committees: Actions during pandemic and lockdown situations. J Postgrad Med 2020;66(3):119-122.

10. Geleneksel ve tamamlayıcı tıp uygulamalarının klinik araștırmaları hakkında yönetmelik. Available from: https://www.resmigazete. gov.tr/eskiler/2019/03/20190309-2.htm (Lastly visited in October 15 th, 2020) 